guided most physicians. Most cases of community acquired pneumonia requiring hospital admission are caused by Streptococcus pneumoniae (34\%); Mycoplasma pneumoniae is the next and most frequent cause (18\%); legionnaires' disease as a sporadic condition is uncommon (2\%); and the combination of influenza and Staphylococcus aureus is rare but disastrous (three cases, all fatal). A microbiological diagnosis was made in two thirds of cases, but this proportion would have been much lower if countercurrent immunoelectrophoresis for pneumococcal antigen had not been performed. The most valuable of the widely available and rapid aetiological investigations were Gram's stain of sputum (insensitive but with a high positive predictive value in pneumococcal infection), blood culture, sputum culture, and cold agglutinin detection (present in 56\% of mycoplasma infections with a specificity of $96 \%$ ).

A fatal outcome was associated with hypotension and tachypnoea on admission and with a rise of the blood urea concentration during admission. Additionally statistical associations between death and increasing age, confusion, leucopenia, and excessive leucocytosis could be shown but only when they were given preference in the order of analysis. The overall mortality was almost $6 \%$. No patient died who had been treated before admission with an antibiotic to which the causative organism was sensitive. Of those who had been treated only a fifth had pneumococcal pneumonia compared with almost half of those who had not received antibiotics. Almost all antibiotics prescribed at home would have been effective against $S$ pneumoniae and hence early treatment selected on the basis of clinical probability is effective in saving lives. The survey's unexpected finding that no fewer than four out of 81 patients with mycoplasmal pneumonia died must surely be a fluke, but it emphasises that these infections must be taken seriously and not dismissed as trivial.

The British Thoracic Society's paper has two important messages. Firstly, the statistical analysis of complex data may not always be as objective as an untutored reader might imagine. Secondly, the management of patients with community acquired pneumonia can be improved. As soon as clinical features of pneumonia are evident in an adult treatment with an antibiotic effective against $S$ pneumoniae should be started and if Mycoplasma infections are prevalent at the time, or there are other suggestive clinical features, erythromycin or tetracycline should also be given. During influenza outbreaks at least one (and, in view of the lethal effect of staphylococcal superinfection, perhaps two) antistaphylococcal antibiotics should be prescribed. Patients should be referred to hospital if they fail to improve with treatment at home, if their diastolic blood pressure is less than $60 \mathrm{~mm} \mathrm{Hg}$, if their respiratory rate is over 30 per minute, or if they are confused or elderly. If the patient is critically ill or if epidemiological evidence suggests legionella infection treatment for that condition should be added. Thus, though we may rightly condemn the indiscriminate prescription of antibiotics, their timely and informed use in patients with pneumonia is vital.

JOHN A INNES

Consultant Physician,

Department of Thoracic Medicine,

East Birmingham Hospital,

Birmingham B9 5ST

\section{Gonadotrophin hormone releasing analogues open new doors in cancer treatment}

Agonist analogues of gonadotrophin releasing hormone cause intense stimulation in the pituitary if given once but then become inhibitory if given repeatedly. This occurs because they are resistant to degradation by pituitary enzymes: they thus block the gonadotroph receptors in the pituitary and make it unresponsive after initial supraphysiological stimulation. ${ }^{1}$ There are many different such analogues, and they have been used to inhibit the production of gonadal hormones and treat hormone responsive cancers.

Hormonal treatments were introduced for prostatic cancer in the 1940s, but only in 1967 did it become apparent that treatment with oestrogen caused excess deaths from cardiovascular disease. ${ }^{2}$ Moreover, neither orchidectomy nor oestrogens confer a significant survival advantage over no treatment, ${ }^{3}$ so other specific treatments were needed that had minimal side effects and were not so mutilating as orchidectomy. Gonadotrophin hormone releasing analogues were discovered to be effective against prostatic cancer in 1980, and the first studies showed response rates equivalent to those achieved with orchidectomy or treatment with oestrogens. $^{5-8}$ Randomised prospective trials confirmed these initial results. One group randomised 199 patients with metastatic prostatic cancer to receive either $3 \mathrm{mg}$ diethylstilboestrol or $1 \mathrm{mg}$ daily of the gonadotrophin releasing hormone analogue leuprorelin (leuprolide): $46 \%$ of those treated with diethylstilboestrol and $38 \%$ of those treated with leuprorelin responded. Only 10 of the 98 patients treated with leuprorelin had cardiovascular side effects compared with 33 of the 101 treated with diethylstilboestrol. ${ }^{9}$ In another randomised study $41 \%$ of 70 patients treated by orchidectomy responded compared with $50 \%$ of those treated with the gonadotrophin releasing hormone analogue decapeptyl. ${ }^{10}$ The duration of the response seems to be the same with conventional treatments and with the analogues. In the leuprorelin study the time to treatment failure was identical in the two groups (46 weeks), and median survival was 146 weeks in those treated with leuprorelin and 136 weeks in those treated with diethylstilboestrol. ${ }^{11}$ In the decapeptyl study median survival was 16 months in those failing treatment with decapeptyl and 13 months in those treated by orchidectomy. ${ }^{12}$

The analogues are thus just as effective as conventional treatments, but are they safer? The fact that the analogues are stimulatory in the first few days of treatment may mean that they exacerbate the disease at first: about a third of patients had minor transient exacerbations and $1 \%$ had appreciable complications. ${ }^{13}$ Analogues are thus contraindicated if the patient has neurological dysfunction or obstructive uropathy. Antiandrogens such as cyproterone acetate or flutamide may reduce these initial problems, but the best antiandrogen regimen has not been established. Giving antiandrogens and analogues together has been suggested as a way of increasing the number of patients responding and the length of response,$^{14}$ and randomised trials to test this hypothesis are in progress. A preliminary report has shown a median time to progression of 14.5 months in 307 patients randomised to receive leuprorelin and flutamide and 12.8 months in 303 patients treated with leuprorelin and placebo (E Crawford et al, American Urology Association, Anäheim, 1987).

Gonadotrophin hormone releasing analogues may now be given as monthly depot injections, which improve com-

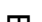


pliance, particularly in elderly patients. ${ }^{1015} 16$ Depot treatment is as effective as daily treatment and has biochemical advantages: serum testosterone concentrations are lower and-unlike some daily treatments-implants are not followed by transient rises in serum luteinising hormone concentrations. ${ }^{17}$ Three monthly depot preparations are being developed, and given initially with an antiandrogen they may be an acceptable alternative to orchidectomy. ${ }^{18}$

The first evidence that gonadotrophin hormone releasing analogues might be effective in breast cancer came in 1975 , when one was shown to inhibit the growth of a rat mammary tumour. ${ }^{19}$ In 1982 two of four premenopausal women with breast cancer responded to the gonadotrophin releasing hormone analogue buserelin. ${ }^{20}$ Later 14 of 45 premenopausal women with breast cancer responded partially to either daily subcutaneous or monthly depot injections with the analogue goserelin. ${ }^{21}$ Patients without oestrogen receptors did not respond, and tumour flare was not seen. Four of 26 women in this study whose disease progressed while taking the analogue later responded to oophorectomy. Responses are also seen to analogues in postmenopausal women with breast cancer: 12 of 31 patients responded to leuprorelin, ${ }^{22}$ one of 18 to buserelin ${ }^{23}$; and one of 12 to goserelin (A L Harris, personal communication). The biochemical basis for response is unknown. All these results require confirmation, but gonadotrophin hormone releasing analogues might prove useful in providing a reversible medical oophorectomy for premenopausal women with breast cancer.

Gonadotrophin hormone releasing analogues have been used in ovarian cancer. The first patient was described in 1985, and responded for one year. ${ }^{24}$ Since then six out of 36 patients have responded to a depot preparation of decapeptyl (H Parmar, personal communication).

About $80 \%$ of patients with advanced Hodgkin's disease are sterilised by combination chemotherapy, but some animal data suggest that gonadotrophin hormone releasing analogues given concurrently with chemotherapy may protect fertility. ${ }^{25}$ Unfortunately, a randomised trial has shown no protection, but the wrong analogue regimen may have been used. ${ }^{26}$

Gonadotrophin hormone releasing analogues have thus helped in studying how hormone dependent cancers respond to treatment, opened up the possibility of a "reversible" oophorectomy for premenopausal women with breast cancer, and provided an alternative to orchidectomy for men with prostatic cancer.

Senior Lecturer and Honorary Consultant in

JONATHAN WAXMAN

Clinical Oncology,

Royal Postgraduate Medical School,

London W12 0HS

1 Coy DH, Schally AV. Gonadotrophin releasing hormone analogues. Ann Clin Res 1978;10: 139-44.

2 The Veterans Administration Co-operative Urological Research Group. Treatment and survival of patients with cancer of the prostate. Surg Gynecol Obstet 1967;124:1011-7.

3 Lepor H, Ross A, Walsh PC. The influence of hormonal therapy on survival of men with advanced prostatic cancer. F Urol 1982;128:335-40.

4 Labrie F, Belanger A, Cusan L, et al. Antifertility effects of LHRH agonists in the male. $\mathcal{F}$ Androl 1980;1:209-28.

5 Tolis G, Ackman D, Stellos A, Mehta A, Labrie F, Fazekas AT. Growth inhibition in patients with prostatic cancer treated with luteinizing hormone releasing hormone agonists. Proc Nat Acad Sci USA 1982;79:1658-62.

6 Borgmann V, Nagel R. AL Abadi H, Schmidt-Gollwitzer M. Treatment of advanced prostatic cancer with LH-RH analogues. Lancet 1982;i:1097-9.

7 Waxman JH, Wass JA, Hendry WF, et al. Treatment with gonadotrophin releasing hormone analogue in advanced prostatic cancer. Br Med f 1983;286:1309-13.

8 Allen JM, O'Shea JP, Mashiter K, Williams G, Bloom SR. Advanced carcinoma of the prostate: treatment with a gonadotrophin releasing hormone agonist. $\mathrm{BrMed} \mathrm{f}$ 1983;286:1607-9.

9 Leuprolide Study Group. Leuprolide versus diethylstilboestrol for metastatic prostatic cancer. NEngl f Med 1984;331:1281-6.

10 Parmar H, Lightman SL, Allen L, Phillips RH, Edwards L, Schally AV. Randomized controlled study of orchidectomy versus long acting D-Trp-6-LHRH microcapsules in advanced prostatic carcinoma. Lancet 1985;ii:1201-5.
11 Garnick MB. Leuprolide versus diethylstilboestrol for previously untreated stage D2 prostate cancer. Urology 1986;27(Suppl):21-6.

12 Parmar H, Edwards L, Phillips RH, Allen L, Lightman SL. Orchidectomy versus long-acting D-Trp-6-LHRH in advanced prostatic cancer. Br $\mathcal{Y}$ Urol 1987;59:248-54.

13 Waxman JH, Man A, Hendry WF, et al. Importance of early tumour exacerbation in patients treated with long acting analogues of gonadotrophin releasing hormone for advanced prostatic cancer. $\mathrm{BrMed} \mathcal{J}$ 1985;291:1387-8.

14 Labrie F, Dupont A, Belanger A, et al. Combination therapy with flutamide and castration (LHRH agonist or orchidectomy) in advanced prostatic cancer: a marked improvement in response and survival. F Steroid Biochem 1985;23:833-41.

15 Williams G, Kerle D, Griffin S, Dunlop H, Bloom SR. Biodegrable polymer luteinizing hormone releasing hormone agonist for prostatic cancer: use of a new peptide delivery system. $\mathrm{Br} M e d-7$ 1984;289:1580-1.

16 Waxman JH, Sandow J, Man A, et al. The first clinical use of depot buserelin for advanced prostatic carcinoma. Cancer Chemother Pharmacol 1986;18:174-5.

17 Kerle D, Williams G, Ware H, Bloom SR. Failure of long-term luteinizing hormone releasing hormone treatment for prostatic cancer to suppress serum luteinizing hormone and testosterone. BrMed f 1984;289:468-9.

18 Fraser HM, Sandow J, Seidel H, Von Rechenberg W. An implant of a gonadotrophin releasing hormone agonist (buserelin) which suppresses ovarian function in the Macaque for 3 to 5 months. Acta Endocrinol (in press).

19 De Sombre ER, Johnson ES, White WF. Regression of rat mammary tumours effected by a gonadoliberin analog. Cancer Res 1976;36:3830-3.

20 Klijn JG, De Jong FH. Treatment with a luteinising hormone releasing hormone analogue (buserelin) in premenopausal patients with metastatic breast cancer. Lancet 1982;ii:1213-6.

21 (billiams MR, Walker KJ, Turkes A, Blamey RW, Nicholson RI. The use of an LH-RH agonis (ICI 118630, Zoladex) in advanced premenopausal breast cancer. Brf Cancer 1986;53:629-36.

22 Harvey HA, Lipton A, Santen RJ, et al. Phase II study of a gonadotrophin-releasing hormone analog (Leuprolide) in postmenopausal advanced breast cancer patients. Proceedings of the American Society of Clinical Oncology/Annals of the Association of Cancer Research 1981:C436.

23 W/axman JH, Harland SJ, Coombes RC, et al. The treatment of postmenopausal women with advanced breast cancer with buserelin. Cancer Chemother Pharmacol 1985;15:171-3.

24 Parmar H, Nicoll J, Stockdale A, et al. Advanced ovarian carcinoma: response to the agonist D-Trp-6-LHRH. Cancer Treat Rep 1985;69:1341.

25 Glode LM, Robinson J, Gould SF. Protection from cyclophosphamide-induced testicular damage with an analogue of gonadotrophin-releasing hormone. Lancet 1981;i:1134-5.

26 Waxman JH, Ahmed R, Smith D, et al. Failure to preserve fertility in patients with Hodgkin's disease. Cancer Chemother Pharmacol 1987;19:159-62.

\section{Self injury and mental handicap}

Whereas suicidal attempts are rare among the mentally handicapped, self injury is common. To cite two personal examples, in one case a boy in a hospital for mentally retarded children died; at necropsy a piece of an old fashioned tin toy was found to have lodged in the oesophagus, whence it had cut into the aorta. In the second case an ingested roll of film had obstructed the terminal ileum. At this level of intelligence (a quotient of 70 or under) there is frequently an undifferentiated appetite, with a "vacuum cleaner" effect. Indiscriminate eating may produce toxic concentrations of lead in the blood in the already mentally handicapped and occasionally selective pica for lead is a prime cause of the handicap.

Uncommonly self injury is an actual component of a condition, such as congenital insensitivity to pain ${ }^{2}$ or the Lesch-Nyhan syndrome. ${ }^{34}$ More usually there is no such link and the self injury results from the impact of an unfavourable environment on a damaged nervous system. In a study in a health region in south east England Oliver et al identified 606 self injuring mentally handicapped people and screened 596 of them. ${ }^{5}$ The types of self injury were very varied: banging the head or body; biting the hands, lips, and fingers or toes; picking and scratching the skin; or poking the eyes and other orifices. Hospital residents inflicted considerably more injury on themselves than those living in hostels and, particularly, those living at home, though the three groups were not comparable for age or degree of handicap.

Self injury seems to be attention seeking and sometimes to be generated by sheer boredom and the lack of other activity or stimulus. All who have worked in mental handicap will know of the problems of overcrowding and understaffing, so 